\title{
Autonomic Function test in person with Obesity aAmong Mid-Western Population of Nepal
}

\author{
Pant BN ${ }^{1}$, Goit RK'르. Panta $\mathrm{M}^{3}$, Neupane $\mathrm{A}^{4}$, Bhargava $\mathrm{P}^{5}$
}

\begin{abstract}
Objective: Autonomic dysfunction qualifies a major public health problems owing to their high prevalence and incidence globally. Among many predisposing factor of autonomic neuropathy such as age, gender, genetic, diabetes etc, obesity also has significant impact Although a lot of progress has been achieved in past decade on accessibility and awareness about health, the obesity remains impending and burgeoning health concern in Nepal. With this trend, we can foresee that the Body Mass Index (BMI) one of the commonly used indirect measure of obesity, might potentially turn out to be one of the leading factor of autonomic dysfunction. Methods: 100 healthy subjects were screened and divided into 2 groups- Group I (BMI>30) and Group II (BMI<30). Height \& weight were measured \& BMI was calculated. Resting heart rate (RHR) was recorded with Lead II of ECG. Blood pressure (BP) and Heart Rate (HR) were recorded in supine position and on immediate standing. Cold pressure test (CPT): Resting BP was recorded in sitting position. Then the subjects were asked to immerse the hand in cold water, and the BP was measured from other hand. Data was analyzed using SPSS 16 (Statistical Package for Social Science). Result: Our result showed that RHR of Group I (79.32 \pm 4.22$)$ was higher than that of Group II (74.38 \pm 7.26$)$. However, on student $-T$ test, BP and HR response to immediate standing $(P=0.34 \& P=0.23$ respectively) were non-significant between group I and group II person. When the correlation was done for the change in $\mathrm{BP}$ in response to CPT in between obese and non-obese person it was found to be significant $(\mathrm{P}=0.04)$. Conclusion: Our data suggests that the BMI can be a predictor of autonomic dysfunction.
\end{abstract}

Key words: Autonomic function, body mass index, cold pressor test, resting heart rate,

\section{INTRODUCTION:}

The prevalence of obesity is rising in developed and developing nations and has been called as "New World Syndrome"1. Obesity is associated with the metabolic risk factors such as high blood pressure (BP), body fat abnormality, and glucose intolerance which may influence the morbidity and mortality due to cardiovascular diseases (CVD) $)^{2,3}$. Most of these deleterious effects are more likely if the excess body fat is mainly stored in the upper body, with abdominal visceral fat being the most critical when evaluating the health risks of obesity ${ }^{2}$. Decreased physical activity, increased consumption of calorie-dense foods and psychosocial stress are few among many factors behind increased obesity among population ${ }^{4}$. Beside being a risk factor for cardiovascular disease, certain cancers and type II diabetes, obesity has also been suggested to be a risk factor for autonomic nervous system (ANS) dysfunction because the energy metabolic balance and cardiovascular system (CVS) is controlled by the ANS ${ }^{5-7}$.

1. Dr. Bhawana Neupane Pant

2. Dr. Rajesh Kumar Goit

3. Dr. Manoj Panta

4. Dr. Ashish Neupane

5. Dr. Pushpa Bhargava

Address for correspondence:

Dr. Bhawana Neupane Pant

Department of Physiology

Nepalgunj Medical College

Chisapani, Banke, Nepal

Email: pant_bhawana@hotmail.com
Body Mass Index (BMI) is a statistical measure of body size based on an individual's weight and height which is regarded as indirect \& easy measure of obesity ${ }^{8}$. Body Mass Index (BMI) as well as other measures of fat distribution including Waist Circumference (WC) and Waist Hip Ratio (WHR) has been correlated with the cardiovascular autonomic dysfunction in many studies ${ }^{9,10}$.

In the past decade, ANS dysfunction and consequently CVD has become burgeoning problem in South Asian population due to changing diet and lifestyle, it is imperative to have similar studies in this population ${ }^{11}$. High-caloric intake increases norepinephrine (NE) turnover in peripheral tissues, raises resting plasma NE concentrations- an indirect measurement of Sympathetic Nervous System (SNS) activity and amplifies the rise of plasma NE in response to stimuli such as upright posture. Moreover high dietary content in fat and carbohydrate has been suggested to acutely stimulate peripheral alpha \& betaadrenergic receptors, leading to elevated sympathetic activity $^{12}$. So far, only few studies confined to specific population has been conducted the south Asian population. Moreover studies have suggested that people of this origin have increased cardiovascular risk due to more centralized deposition of body fat with higher mean of WC \& WHR to Europians ${ }^{11,13,14}$. It has recently been shown that South Asian children have higher body mass adjusted Blood pressure (BP) levels than white American-Caucasian children ${ }^{15}$. Furthermore, World Health Organization (WHO) has also lowered the cut offs for overweight and obesity for the Asian population, which again points to the fact that Asian and 
especially south Asian population suffers from an overall higher obesity related autonomic hypofunction risk $^{16}$. Therefore understanding the relation of adiposity with cardiovascular autonomic dysfunction into specific population is essential. Although a lot of progress has been achieved in past decade on accessibility and awareness about health, the obesity remains impending and burgeoning health concern in Nepal. With this trend, the aim of this study was to evaluate the autonomic neuropathy in obese person by evaluating the sympathetic and parasympathetic tests.

\section{MATERIAL AND METHODS}

This cross sectional prospective study was conducted in Department of Physiology, Nepalgunj Medical College Teaching Hospital (NGMCTH) from 2016-12-5 to 2017-4-6. Total 100 healthy subjects of the age range 30 to 55 years who gave the consent were included from the staff and student population in the study and were divided into two groups- Group I (BMI>30) and Group II (BMK 30$)$. The subjects with the history of diabetes, hypertension (HTN) and known history of chronic illness, and known neuropathy of any other illness, current smokers were excluded from this study.

\section{Anthropometric Measurement:}

The anthropometric measurement was measured by standard procedures. The height was measured by stadiometer with subjects having their shoes removed. ${ }^{17}$ The body weights of the subjects was measured in light clothing, without shoes ${ }^{17}$. BMI was determined by dividing weight in kilogram $(\mathrm{kg})$ by height in square meter $\left(\mathrm{m}^{2}\right)^{18}$.

Autonomic Function Test:

Resting heart rate (RHR) was recorded with Lead II of ECG. On the ECG, instantaneous $R$ wave-to-R wave (RR) interval was evaluated and heart rate was calculated by using the formula: 1500/ RR interval $(\mathrm{mm})^{19}$.

\section{Heart Rate (HR) response to immediate standing from supine position \\ Heart Rate (HR) was recorded in supine position when subjects are in fully resting state and on immediate standing with Lead II of Electrocardiograph (ECG).}

\section{Blood Pressure (BP) response to immediate standing from supine position}

$\mathrm{BP}$ was recorded with the help of mercury sphygmomanometer in supine position when subjects are in fully resting state and on immediate standing. The measurements of systolic (SBP) and diastolic blood pressure (DBP) were taken and Mean arterial blood pressure (MAP) was calculated for each of the two readings taken for $S B P$ and $D B P^{20,21}$.

Cold pressure test (CPT): Resting BP was recorded in sitting position. Then the subjects were asked to immerse the hand in cold ice water with temperature maintained at $4-6^{\circ} \mathrm{C}$, and the BP was measured from other hand after 1 minute.

\section{Data Analysis:}

Data was analyzed with statistical IBM SPSS statistics version 16. Different anthropometric and cardiovascular variables were compared between the groups using Students's independent $t$ test and the data are represented as mean standard deviation (SD).

\section{RESULT}

\begin{tabular}{|l|c|c|c|}
\hline $\begin{array}{l}\text { Distribution of subject } \\
\text { according to gender }\end{array}$ & Male & Female & Total \\
\hline Group I & 37 & 13 & 50 \\
\hline Group II & 35 & 15 & 50 \\
\hline Total & 72 & 28 & 100 \\
\hline
\end{tabular}

Table I: Showing demographic representation of the subjects. Among the 100 subjects examined (age 30 to 55 years) females were 28 and the males were 72 in number

\begin{tabular}{|l|c|c|c|}
\hline & Group I Mean \pm S.D & Group II Mean \pm S.D & P value (Independent T-Test) \\
\hline Difference in SBP & $11.08 \pm 5.48$ & $12.5 \pm 6.65$ & 0.24 \\
\hline Difference in DBP & $7.68 \pm 4.26$ & $7.48 \pm 3.72$ & 0.80 \\
\hline Difference in MAP & $8.81 \pm 3.65$ & $8.81 \pm 3.65$ & 0.64 \\
\hline Difference in HR & $4.04 \pm 4.04$ & $4.66 \pm 2.59$ & 0.36 \\
\hline
\end{tabular}

The $p<0.05$ was considered statistically significant

Table II: Blood Pressure (BP) \& Heart rate (HR) response to immediate standing from supine position of group I \& group II 


\begin{tabular}{|l|c|c|c|}
\hline Variables & Group I & Group II & P-value \\
\hline Age & $44.24 \pm 4.82$ & $43.52 \pm 7.04$ & 0.24 \\
\hline BMI & $32.5 \pm 1.84$ & $27.88 \pm 1.99$ & $0.02^{*}$ \\
\hline SBP(Supine) & $126.84 \pm 6.88$ & $123.22 \pm 8.54$ & 0.69 \\
\hline DBP(Supine) & $90.98 \pm 6.47$ & $80.84 \pm 7.26$ & 0.47 \\
\hline MAP(Supine) & $102.93 \pm 5.38$ & $94.96 \pm 7.27$ & 0.08 \\
\hline SBP(Standing) & $115.76 \pm 6.40$ & $110.72 \pm 7.26$ & 0.23 \\
\hline DBP (Standing) & $83.42 \pm 6.74$ & $73.36 \pm 6.69$ & 0.86 \\
\hline MAP(Standing) & $94.19 \pm 5.34$ & $85.81 \pm 6.73$ & 0.83 \\
\hline RHR & $79.32 \pm 4.22$ & $74.38 \pm 7.26$ & $0.00^{*}$ \\
\hline HR(Supine) & $79.32 \pm 4.22$ & $74.38 \pm 7.26$ & 0.10 \\
\hline HR(Standing) & $83.36 \pm 7.03$ & $79.02 \pm 4.51$ & $0.01^{*}$ \\
\hline SBP (Baseline) & $126.84 \pm 6.88$ & $123.10 \pm 8.33$ & 0.62 \\
\hline DBP(Baseline) & $91.24 \pm 6.42$ & $80.64 \pm 7.06$ & 0.53 \\
\hline MAP(Baseline) & $103.01 \pm 5.19$ & $94.79 \pm 7.04$ & 0.75 \\
\hline SBP(CPT) & $133.34 \pm 6.03$ & $128.68 \pm 8.54$ & 0.18 \\
\hline DBP(CPT) & $97.94 \pm 5.16$ & $86.80 \pm 6.44$ & 0.20 \\
\hline MAP(CPT) & $109.71 \pm 4.87$ & $98.09 \pm 6.50$ & 0.80 \\
\hline
\end{tabular}

*The $p<0.05$ was considered statistically significant

Table III: Showing the anthropometric and hemodynamic variable of groupl \& group II

\begin{tabular}{|l|c|c|c|}
\hline & Mean \pm S.D ( Before CPT) & Mean + S.D (After CPT) & P value \\
\hline SBP & $126.56 \pm 6.61$ & $133.34 \pm 6.032$ & $0.00^{*}$ \\
\hline DBP & $91.2 \pm 6.42$ & $97.94 \pm 5.16$ & $0.00^{*}$ \\
\hline MAP & $103.01 \pm 5.19$ & $109.97 \pm 4.87$ & $0.00^{*}$ \\
\hline
\end{tabular}

*The $p<0.05$ was considered statistically significant

Table IV: Comparison of blood pressure (BP) before and at 1 minute after Cold Pressor Test (CPT) of Group I

\begin{tabular}{|l|c|c|c|}
\hline & Mean \pm S.D ( Before CPT) & Mean + S.D (After CPT) & P value \\
\hline SBP & $123.10 \pm 8.33$ & $128.68 \pm 8.54$ & $0.00^{*}$ \\
\hline DBP & $80.64 \pm 7.06$ & $86.80 \pm 6.44$ & $0.00^{*}$ \\
\hline MAP & $94.73 \pm 7.04$ & $98.09 \pm 6.50$ & $0.00^{*}$ \\
\hline
\end{tabular}

The $p<0.05$ was considered statistically significant

Table V: Comparison of blood pressure (BP) before and at 1 minute after Cold Pressor Test (CPT) of Group II

\begin{tabular}{|l|c|c|c|}
\hline & $\Delta$ in BP Group I & $\Delta$ in BP Group II & P value (Independent T-Test) \\
\hline SBP & $6.94 \pm 3.86$ & $5.58 \pm 2.67$ & $0.04^{*}$ \\
\hline DBP & $6.7 \pm 4.5$ & $6.16 \pm 3.27$ & 0.49 \\
\hline MAP & $6.7 \pm 4.5$ & $3.3 \pm 3.28$ & $0.00^{*}$ \\
\hline
\end{tabular}

The $p<0.05$ was considered statistically significant

Table VI: Difference $(\Delta)$ in BP before and after the Cold Pressure Test (CPT) 


\section{DISCUSSION}

The present study was designed to evaluate any alternation in cardiac autonomic function in obese and non-obese person by evaluating the sympathetic and parasympathetic tests. Many studies have reported the relation of Autonomic Dysfunction, especially of Cardiovascular System with anthropometric parameters such as BMI, WHR, WC, Hip Circumference (HC), Subcutaneous Fat (SF) etc ${ }^{2-3,22-23}$. There are inconsistencies in their finding, which can be ascribed to the diversity in sample population. Additionally, there might be some methodological differences behind inconsistency in results. However one should not undermine that correlation of anthropometric variable with fitness parameters such as $B P$ and pulse rate (PR) can be affected by lifestyle, exercise habits, over all environment and genetics among the population. Therefore our study was aimed to determine the relationship of parameters in small cohort of population in Nepal, where any of such studies has not been reported.

The study screened 128 random subjects attending NGMCTH; among which 100 subjects who met the inclusion criteria were selected. Provided the subjects included in this study were not diagnosed with HTN in past five years. Among the 100 subjects $28 \%$ of the study population were female and $72 \%$ were male.

The present study provides the significance of BMI with RHR, change in BP \& HR from supine to immediate standing, and change in BP before \& after the CPT suggesting the better anthropometric for predicting Autonomic dysfunction in both sexes.

The results presented in the table II indicates that the RHR of Group I was higher than that of Group II. Our result also confirms with some of other studies that have found that both RHRst (standing) and RHRsup (supine) are significantly greater in persons having general obesity or central obesity as compared to non-obese individuals $\mathrm{s}^{24}$. Obesity and the cardiac autonomic nervous system are intrinsically related. A $10 \%$ increase in body weight is associated with a decline in parasympathetic tone, accompanied by a rise in mean HR, and conversely, HR declines during weight reduction ${ }^{25-27}$.

Reductions in vagal activity with increment in weight may be one mechanism for the arrhythmias and other cardiac abnormalities that accompany obesity. The result also indorses the statement from one of research article that higher heart rate might predispose to the development of obesity and diabetes mellitus (DM), implying the role of sympathetic system in the development of obesity and $\mathrm{DM}^{28}$. In obese subjects a reduction in body weight exerts a marked reduction in sympathetic activity owing to central sympathoinhibition. This could be the consequence of a restoration of the baroreflex control of the cardiovascular system with weight $\operatorname{loss}^{29}$.
However, on student- $T$ test, $\mathrm{BP}$ and $\mathrm{HR}$ response to immediate standing ( $P=0.64 \& P=0.36$ respectively) were found to be nonsignificant between obese and non-obese person as shown in the table II. The non-significant relation of BP and HR with change in posture in the present study might be due to fewer sample size of different age groups. Moreover the HRstanding was statistically significant in between two groups $(p=0.01)$. Nevertheless the association with HR has been reported in many studies ${ }^{24}$.

In table VI when the significance was seen for the change in BP in response to CPT in between obese and non-obese person it was found to be significant for SBP \& MAP ( $P=0.04,0.00$ respectively). However, the difference in mean DBP recorded before and after CPT was non-significantly $(p=0.49)$ more in group I $(6.7 \pm 4.5 \mathrm{mmHg})$ as compared to group II $(6.16 \pm 3.27$ $\mathrm{mmHg}$ ). The DBP is the direct measure of total peripheral resistance (TPR) and is less fluctuating that SBP which is mainly a direct measure of cardiac output ${ }^{21}$. However earlier studies have reported affect in DBP associated with obesity ${ }^{30}$. MAP shows strongest statistical significance with CPT. Results of our study correlate with observations made by other workers ${ }^{31}$.

It may be because of the fact that the CPT triggers the sympathetic nerve activity, and impaired CPT in overweight persons may be due to hypo function of sympathetic Nervous System ${ }^{31}$. The causes of impaired sympathetic activity in obesity are not fully understood, but recent studies suggest that hormones, such as leptin, released from fat cells may directly stimulate multiple regions of the hypothalamus, which, in turn, have an excitatory influence on the vasomotor centers of the brain medulla ${ }^{32}$.

Therefore our study have found that BMI is a good indicator of cardiovascular autonomic dysfunction risk factors, and should be incorporated into a public message and awareness programs.

\section{CONCLUSION}

Thus our study shows that in person with obesity with higher $\mathrm{BMI}$ are at high risk for autonomic dysfunction as compared to person with normal weight. Relevant anthropometric index can serve as excellent indicators if used based of scientific validation.

\section{REFERENCES}

1. NIH Guide. Pathophysiologic mechanism of obesity associated cardiovascular disease. NHLBI.2002 Jan.

2. Lahti-Koski M. Body mass index and obesity among adults in Finland [Online]. 2001 Nov 9 [cited 21 Dec 2014]; Available from: URL:http://ethesis.helsinki.fi/julkaisut/laa/kansa/vk/ lahtikoski/bodymass.pdf.

3. Oda E, Kawai R. Age and gender-related differences in correlations between abdominal obesity and obesity-related metabolic risk factors in Japanese. Intern Med 2009;48:497-02.

4. Gupta R, Rastogi P, Sarna M, Gupta VP, Sharma SK, Kothari K. 
Body-mass index, waist-Size, waist-hip ratio and cardiovascular risk factors in urban subjects. JAPI 2007 Sep;55:621-7.

5. Hirsch Jules, Mackintosh M. Ronald. Measuring activity of the autonomic nervous system in humans. Obes Res. 2003; 11: 2-4.

6. Bray GA. Autonomic and endocrine factors in the regulation of energy balance. Fed Proc. 1986; 45(5):1404-1410.

7. Messina G, Luca VD, Viggiano A, Ascione A, T lannaccone, Chieffi S, Monda M. Autonomic Nervous System in the Control of Energy Balance and Body Weight:Personal Contributions. Neurol Res Int. 2013(2013): 5 pages. DOI: http://dx.doi.org/10.1155/2013/639280.

8. Body mass index [Online]. 2013 July 18 [cited 2016 Dec 21]; [12 screens]. Ava il a ble from: URL: http://en.wikipedia.org/wiki/Body_mass_index.

9. Quadri R, Maule S, Flecchia D, Veglio M, Rovera L, Rosa C, Zanone $M$, Fonzo D. Autonomic nervous system activity in obese subjects before and after caloric restriction. Funct Neurol. 1990; 5(3):273276.

10. Valensi P, Thi BN, Lormeau B, Paries J, Attali JR. Cardiac autonomic function in obese patients. Int J Obes Relat Metab Disord. 1995 Feb;19(2):113-118.

11. Paul P, Thomas $G$, George AB, Yuling H, Judith SS, Xavier FS, Robert HE. Obesity and Cardiovascular Disease: pathophysiology, evaluation, and effect of weight Loss: an update of the 1997 American Heart Association Scientific Statement on Obesity and Heart Disease from the Obesity Committee of the Council on Nutrition, Physical Activity, and Metabolism. 2006 Feb 14;113(6):898-918. Epub 2005 Dec 27: DOI:10.1161/CIRCULATIONAHA.106.171016.

12. Grassi G, Seravalle G, Cattaneo BM, Bolla G, Lafranchi A, Colombo M, Giannattasio C, Brunani A, Cavagnini F, Mancia G. Sympathetic activation in obese normotensive subjects. Hypertension 1995;25:560-563.

13. Keigue PM, Saha B, Marmot MG. Relation of central obesity and insulin resistance with prevalence and cardiovascular risk in South Asian. Lancet 1991;337:382-7.

14. Ghosh A, Bose K, Das AB. Comparison of anthropometric characteristics between normotensive and hypertensive individuals among a population of Bengalee hindu elderly men in Calcutta. India J R Soc Health 2000;120:100-6.

15. Jafar TH, Islam M, Poulter N, Hatcher J, Schmid CH, Levey AS et al. Children in South Asia have higher body mass-adjusted blood pressure levels than white children in the United States: a comparative study. Circulation. 2005 Mar 15;111(10):1291-7.

16. Enas EA. Coronary artery disease epidemic in Indians: a cause for alarm and call for action. J Indian Med Assoc 2000;98:694-02.

17. Lohman TG, Roche AF, Martorell R, editors. Anthropometric Standardization Reference Manual. Champaign II: Human Kinetics; 1988. p. 143-9.

18. Nichols SD, Cadogan, F. Anthropometric reference values in an Apro-Caribben adolescent population. Amer J Human Biol 2008;20:51-8.

19. Heart Rate [Online]. 2003 Aug 26 [cited 2016 Dec 20]; [4 screens]. Available from; URL: https://en.wikipedia.org/wiki/Heart_rate.

20. Weinsier RL, Norris DJ, Birch R, Bernstein RS, Wang J, Yang MU et al. The relative contribution of body fat and fat pattern to blood pressure level. J Amer Heart Assoc 1985;7:578-85.

21. Pal GK, Pal P, Nanda N. Text book of Medical Physiology. 2nd ed. Delhi: Tarun Ahuja for Ahuja Publishing House; 2012. p. 647.

22. Gupta R, Rastogi P, Sarna M, Gupta VP, Sharma SK, Kothari K. Body-mass index, waist-Size, waist-hip ratio and cardiovascular risk factors in urban subjects. JAPI 2007 Sep;55:621-7.

23. Knowles KM, Paiva LL, Sanchez SE, Lopez LR, Yasuda MB, Yanez ND et al. Waist Circumference, Body Mass Index, and Other Measures of Adiposity in Predicting Cardiovascular Disease Risk Factors among Peruvian Adults. Int J Hypertens. 2011; 2011: 931402.

24. Yar T. Resting heart rate and its relationship with general and abdominal obesity in young male Saudi university students. Pak J Physiol 2010;6(1):6-13.

25. Seccareccia F, Pannozzo F, Dima F, Minoprio A, Menditto A, Lo NC et al. Heart rate as a predictor of mortality: the MATISS project. Am J Public Health 2001;91(8):1258-63.

26. Hirsch J, Leibel RL, Mackintosh R, Aguirre A. Heart rate variability as a measure of autonomic function during weight change in humans. Am J Physiol 1991;261(6.2):1418-23.

27. Kannel WB, Kannel C, Paffenbarger RS, Jr., Cupples LA. Heart rate and cardiovascular mortality: the Framingham Study. Am Heart J 1987;113(6):1489-94.

28. Shigetoh $Y$, Adachi $H$, Yamagishi S, Enomoto M, Fukami A, Otsuka $M$ et al. Higher heart rate may predispose to obesity and diabetes mellitus: 20 -year prospective study in a general population. Am J Hypertens 2009; 22(2):151-5.

29. Grassi G. Adrenergic overdrive as the link among hypertension, obesity, and impaired thermogenesis: lights and shadows. Hypertension 2007;49(1):5-6.

30. Rossi RC, Vanderlei LCM, Goncalves ACCR, Vanderlei FM, Bernardo AFB, Yamada KMH el al. Impact of obesity on autonomic modulation, heart rate and blood pressure in obese young people. 2015 Dec; 193:138-141 DOI: https://doi.org/10.1016/j.autneu.2015.07.424.

31. Simone DG, Mancini M, Turco S, Marotta I, Gaeta I, Lannuzzi R, Ferrara LA, Mancini M. Cardiovascular response to the cold test in obese subjects. Effect of a hypocaloric, normal sodium diet. Minerva Endocrinol. 1990 Oct- Dec; 15(4):231-233.

32. Hall JE. Guyton and Hall textbook of medical physiology. 12th ed. Philadelphia: Elsevier Inc.; 2011. p. 225. 